\title{
Unburnt carbon and iron content in the ash and slag thermal power plants
}

\author{
Elena Yu. Temnikova ${ }^{1, *}$, Alexander R. Bogomolov ${ }^{1,2}$, and Alexey A. Lapin ${ }^{1}$ \\ ${ }^{1}$ Gorbachev Kuzbass State Technical University, 650000 Kemerovo, Russia \\ ${ }^{2}$ Kutateladze Institute of Thermophysics SB RAS, 630090 Novosibirsk, Russia
}

\begin{abstract}
The work is devoted to the determination of the content of carbon underburn and iron in the fly ash of thermal power plants. The results of determining the mechanical underburning by fractions for three stations are presented to show that the stations have a slight underburning besides the Tom-Usinsk SDPP. In addition, there is a general regularity showing a 4-10 times higher content of remnant carbon in fly ash than in slag. Data are presented on the composition of elements of sulfur, calcium and iron in the original fly ash and in the separated magnetic fraction in a one-step separation on a magnetic analyzer in water.
\end{abstract}

\section{Introduction}

Ash-slag materials (ASM) of thermal power plants (TPP) include a significant amount of the basic and acid oxides, and small concentrations of oxides of zinc, titanium, nickel, lead, barium, vanadium, and others.

The mineral components of coals after flaring at TPP can be considered technogenic wastes, when they are transported by different transport modes and stored in designated areas, or complex and diverse raw materials, suitable for processing by the well known methods in order to obtain demanded products in various industries.

The extraction products are the known ash-slag materials containing silicon oxides (57$62 \%$ ), aluminum oxides (20-25\%) and iron oxides (3.12\%), and hollow aluminosilicate microspheres (1-2\%) formed at high-temperature coal flaring.

According to the data of different authors, the annual volume of ASM production by the coal plants of Russia is from 34 to 50 million tons. Only $13-14 \%$ of these materials are recycled and used in industry.

\section{Problem statement}

Among the ASM components, the hollow microspheres, no-microsphere fly ash and slag achieved the most common application. The important characteristic is the presence or absence of unburnt carbon and iron oxide in these separated fractions for potential industrial consumers.

The work purpose is to study the content of remnant carbon and iron of fly ash and slag.

* Corresponding author: teu.pmahp@,kuzstu.ru 


\section{Results and discussion}

The dispersion analysis of fly ash from the Kemerovo State District Power Plant (KemSDPP) (Russia, Kuzbass), the Tom-Usinsk state district power plant (TU SDPP) (Russia, Kuzbass), and the Novo-Kemerovo heat and power plant (NK HPP) (Russia, Kuzbass) allowed it to be divided into fractions, studied to determine the content of remnant carbon. Mechanical underburning (the presence of remnant carbon) was determined by burning out the organic mass from ASM according to GOST 11022-95 "Solid mineral fuel. Methods for determination of ash content". The results of ashing are presented in Table 1.

Table 1. The results of determination of the remnant carbon on fractions.

\begin{tabular}{|c|c|c|c|}
\hline \multirow{2}{*}{ Faction, $\boldsymbol{\mu m}$} & \multicolumn{3}{|c|}{ The content of remnant carbon in fly ash, \%, mass. } \\
\cline { 2 - 4 } & KemSDPP & TU SDPP & NK HPP \\
\hline $0-50$ & 0.7387 & 9.08 & 1.96 \\
\hline $50-63$ & 1.6987 & 7.78 & 2.72 \\
\hline $63-80$ & 1.5196 & 9.25 & 3.7 \\
\hline $80-100$ & 2.0951 & 9.77 & 3.71 \\
\hline $100-160$ & 5.2857 & 14.8 & 5.71 \\
\hline $160-200$ & 4.8478 & 14.48 & 5.81 \\
\hline $200-250$ & 2.2152 & 14.16 & 8.51 \\
\hline $250-300$ & 0 & 0 & 4.98 \\
\hline$>300$ & - & - & 0 \\
\hline
\end{tabular}

Data analysis of the content of remnant carbon in fractionated fly ash shows that the ash particles formed in boiler of Kemerovo SDPP during combustion of pulverized coal have little carbon residue. The maximum occurs at a particle size of about 150 microns. Ash particles formed during combustion of pulverized coal at the Novo-Kemerovo HPP have maximal underburning degree at sizes of about 220 microns. The greatest amount of unburnt carbon in fly ash belongs to Tom-Usinsk SDPP (about 14\%) with a particle size of $120-220 \mu \mathrm{m}$. A significant underburning is present at 25-50 microns (about 9\%) in comparison with carbon underburning in the same classes of fly ash at Kemerovo SDPP and Novo-Kemerovo HPP (about 1-2\%).

It should be noted that fly ash mainly consists of particles of $0-100 \mu \mathrm{m}$ in size. The number of particles with the weight of less than 100 microns is $\approx 92 \%$ for KemSDPP, $\approx$ $89 \%$ for TU SDPP, and $\approx 88 \%$ for NK HPP [1]. That is, the share of unburned carbon is concentrated in this fraction.

The results of Table 1 show that the gas-dynamic and temperature operating mode in the boiler furnaces of Tom-Usinsk SDPP require scrutiny. It can be assumed that coal in the boiler is burned at high temperatures, at which the mineral component, having a low softening point, passes into liquid state. Under these conditions, part of the unburned carbon is enveloped by the liquid phase of the mineral component, which prevents oxidation and combustion of carbon located in the protective envelope.

Further, when the temperature of flue gases decreases while moving along the screen tubes and flue duct of the convective part together with the liquid particles, the mineral parts of particles transform into the solid state and non-oxidized carbon remains in the "shell". This process is similar to formation of slags and druses in the layered furnaces, where much unoxidized carbon remains under the shell of the mineral component. To reduce the formation of large slag granulate and achieve more complete combustion of carbon, it is recommended to carry out frequent shuffling and use a thin height of the coal layer on the grate in the layer furnaces. 
Table 2 presents the results of instrumental measurements of the remnant carbon and iron content in ash and slag samples from four stations (here data on the Belovo state district power plant (BelSDPP) is included). Element content was determined using the scanning electron microscopy method using the scanning electron microscope JEOL JSM6390 LA with the energy-dispersive X-ray detector JED 2300 of the Collective Use Center of the Federal Research Center for Coal and Coal Chemistry, RAS.

Table 2. Results of determining remnant carbon and iron.

\begin{tabular}{|c|c|c|c|c|}
\hline \multirow{2}{*}{ Element } & \multicolumn{4}{|c|}{ The content of remnant carbon and iron in fly ash/slag, \%, mass. } \\
\cline { 2 - 5 } & KemSDPP & BelSDPP & TU SDPP & NK HPP \\
\hline $\mathrm{C}$ & $2.63 / 0.23$ & $2.57 / 0.66$ & $4.86 / 4.77$ & $2.98 / 0.27$ \\
\hline $\mathrm{Fe}$ & $4.04 / 1.35$ & $2.86 /-$ & $3.71 / 0.04$ & $2.19 / 1.36$ \\
\hline
\end{tabular}

It can be seen from Tables 1 and 2 that there is a general dependence showing 4-10 times higher content of remnant carbon in the fly ash as compared with slag at the KemSDPP, BelSDPP and NK HPP. A slight difference, with observance of the tendency noted by the authors, was revealed at Tom-Usinsk SDPP.

Probably, this is due to the combustion regimes of pulverized coal fuel, which involve not only identical content of remnant carbon in the ash and slag of the TU SDPP, but about 2 times higher carbon content as compared to ash and slag at other plants.

Table 2 shows that there is essentially less amount of iron compounds in the slag than in the ash. Iron can be in the fly ash and in the slag as a separate element of $\mathrm{Fe}$, as iron oxide (II, III) $\left(\mathrm{Fe}_{2} \mathrm{O}_{3}\right.$ and/or $\mathrm{Fe}_{3} \mathrm{O}_{4}\left(\mathrm{FeO} \cdot \mathrm{Fe}_{2} \mathrm{O}_{3}\right.$ in the form of magnetite or iron cinder), as iron carbonate (II) $\mathrm{FeCO}_{3}$, as ironic sulphate $\mathrm{FeSO} 4$, which in the presence of sodium carbonate $\mathrm{Na}_{2} \mathrm{CO}_{3}$ or calcium carbonate $\mathrm{CaCO}_{3}$ in an inert medium passes into iron carbonate $\mathrm{FeCO}_{3}$ to form sodium sulfate $\mathrm{Na}_{2} \mathrm{SO}_{4}$ or calcium sulfate $\mathrm{CaSO}_{4}$. At that, sulfuric or sulfurous oxides form solid mineral sulfates either with sodium or with calcium, or with iron, i.e., there is binding of gaseous sulfur oxides formed during combustion of coal with a small amount of sulfur. It should be noted that iron carbonates $\mathrm{FeCO}_{3}$, formed during combustion at temperatures above $500^{\circ} \mathrm{C}$, are converted to iron (II) oxides with emission of carbon dioxide gas $\mathrm{CO}_{2}$. This mechanism explains the higher content of iron oxides in fly ash than in slag.

Thus, at magnetic fraction separation from the total composition of fly ash, an increase in concentration of iron-containing compounds should occur; we assume that there should be more iron sulphates in the form of $\mathrm{FeSO}_{4}$, calcium sulfates $\mathrm{CaSO}_{4}$ and $\mathrm{Fe}_{2} \mathrm{O}_{3}$ oxides (in the iron equivalent), as well as an increase in concentration of sulfur compounds (in the sulfur equivalent).

Data on the composition (in terms of the element) of elements of sulfur, calcium and iron in the original fly ash and in the separated magnetic fraction are presented in Table 3 in a one-step separation on a magnetic analyzer in water.

It can be seen from Table 3 that in the magnetic fraction (in the element equivalent), there are 2-3 times more elemental iron, separated by one-stage wet magnetic separation on a magnetic analyzer, than in the original fly ash. An increase in concentration of sulfur with simultaneous increase in calcium shows that sulfur can be in the form of iron and calcium sulphates with a high probability. 
Table 3. Data on the composition of elements of sulfur, calcium and iron in the ash and the separated magnetic fraction.

\begin{tabular}{|c|c|c|c|c|c|c|}
\hline \multirow{3}{*}{ Element } & \multicolumn{6}{|c|}{ Content of elements, \%, mass. } \\
\cline { 2 - 7 } & \multicolumn{2}{|c|}{ BelSDPP } & \multicolumn{2}{c|}{ TU SDPP } & \multicolumn{2}{c|}{ NK HPP } \\
\cline { 2 - 7 } & ash & $\begin{array}{c}\text { magnetic } \\
\text { fraction }\end{array}$ & ash & $\begin{array}{c}\text { magnetic } \\
\text { fraction }\end{array}$ & ash & $\begin{array}{c}\text { magnetic } \\
\text { fraction }\end{array}$ \\
\hline $\mathrm{S}$ & 0.07 & 0.11 & 0.18 & 0.36 & 0.22 & 0.36 \\
\hline $\mathrm{Ca}$ & 2.33 & 8.48 & 2.18 & 5.48 & 1.58 & 4.19 \\
\hline $\mathrm{Fe}$ & 2.86 & 4.79 & 3.71 & 10.51 & 2.19 & 7.90 \\
\hline
\end{tabular}

\section{Conclusion}

Maximal carbon underburning in fly ash of the studied plants is observed in the fractions of 100-200 microns. A significant amount of remnant carbon is available in fractional composition of fly ash with the particle size of above 200 microns at Tom-Usinsk SDPP and Novo-Kemerovo HPP plants. However, the share of these fractions is insignificant in the total amount of waste (materials) stored in the ash dump that pollute the environment. It should be noted that the method of fly ash capturing at Tom-Usinsk SDPP and NovoKemerovo HPP differs from the Kemerovo SDPP. These differences require special attention when analyzing the share of coal underburning at the plants.

To increase the boiler efficiency, the model thermal and gas dynamic calculations with comparison of experimental results are required for the detailed analysis of the reasons for underburning of large particles of pulverized coal at the plants.

The tendency to a higher content of remnant carbon and iron in the fly ash in comparison with the slag removed by the liquid method is shown.

It has been determined that the sulphurous compounds of coal (organic, pyrite and sulphate- sulphide) migrate mainly to iron and calcium sulfates in the process of combustion.

The studies were financially supported by the Russian Foundation for Basic Research and Department of Education and Science of Kemerovo region in the framework of scientific project No. 16-48420871, "r_a" and Agreement No. 6 of December 15, 2016.

\section{References}

1. E.Yu. Temnikova, A.R. Bogomolov, N.V. Tiunova, A.A. Lapin, Vestnik KuzSTU (2017) [in Russian] 